\title{
THE BLOOD SUPPLY OF THE OESOPHAGUS IN RELATION TO OESOPHAGEAL ATRESIA*
}

\author{
BY \\ JAMES LISTER $\dagger$ \\ From the Nuffield Department of Paediatric Surgery, Institute of Child Health, University of London, \\ and the Sheffield Children's Hospital, Western Bank, Sheffield
}

Over 100 years ago vascular insufficiency was suggested as a cause of intestinal atresia. This remained a popular hypothesis until Tandler (1902) produced his work on the development of the duodenum, showing a stage at which the lumen was obliterated and postulating that arrest of development at this stage and failure of recanalization produced atresia. This theory was applied indiscriminately to all parts of the gut and continues to be quoted as a cause of oesophageal atresia, although Johns (1952) demonstrated that in human development the oesophagus was never completely occluded. It is partly because of a lack of knowledge of normal development that the pathogenesis of congenital abnormalities, particularly those of the alimentary tract, is not fully understood.

Two facts, however, must be accepted. First, most congenital defects can be produced by any one of several agents acting during a certain period of embryonic development, and a specific agent may produce different anomalies when applied at different stages of development. Secondly, the normal development of the embryo must depend on an adequate oxygen supply and nutrition; and after the foetal heart begins to beat in the fourth week $(4 \mathrm{~mm}$. stage) the development of the various organs must depend on the development of their blood vessels and the maintenance of a normal blood supply through those vessels.

Louw (1959) showed experimentally that various small bowel atresias could be produced by surgical interference with the blood supply to the gut of puppies in utero. In oesophageal atresia Keith and Spicer in 1906 found anomalous aortic arches and anomalous right subclavian arteries, and Fluss and Poppen (1951) more recently suggested that anoma-

\footnotetext{
- A paper read at a meeting of the British Association of Paediatric Surgeons in Sheffield, July 1963.

$\uparrow$ Present address: The Children's Hospital, Western Bank, Sheffield, 10.
}

lies in arteries and fourth aortic arch remnants might be more common than was appreciated. The suggestion of these authors was that oesophageal atresia could be produced by pressure from abnormal vessels.

A careful dissection of the post-mortem material of 15 cases of oesophageal atresia at the Queen Elizabeth Hospital for Children in London revealed a large number of associated anomalies. There were six with severe cardiac lesions, four with imperforate ani and six with club foot or absent digits. Only two, however, had abnormal subclavian arteries, and although this is considerably higher than the normal frequency of $0.2 \%-1 \%$ in Europeans and $2 \cdot 5 \%-9.7 \%$ in American negroes quoted by De Garis, Black and Riemenschneider (1933), it cannot be regarded as the primary cause of oesophageal atresia.

The previous suggestions as to pathogenesis were that an aberrant right subclavian artery, or the arteria aberrans, a remnant of the fourth right aortic arch, would interfere with oesophageal development by pressure as they crossed behind it either during the process of separation of the trachea from the oesophagus or at a later stage. The usual argument against this is that it is highly improbable that atresia could be produced by vascular pressure, and much more likely that the absence of an oesophagus would allow a vessel to persist instead of disappearing during development; this argument seems perfectly valid, but the anomaly could still be produced by the vascular anomaly since the vascular anomaly could be responsible for a deficient blood supply to the oesophagus and possibly to the trachea as well.

Most anatomical textbooks deal quite briefly with the blood supply of the oesophagus, describing branches from the inferior thyroid artery, direct branches from the descending aorta, branches from the left gastric artery and from the left phrenic artery. A more detailed study of the distribution of these branches was attempted. 


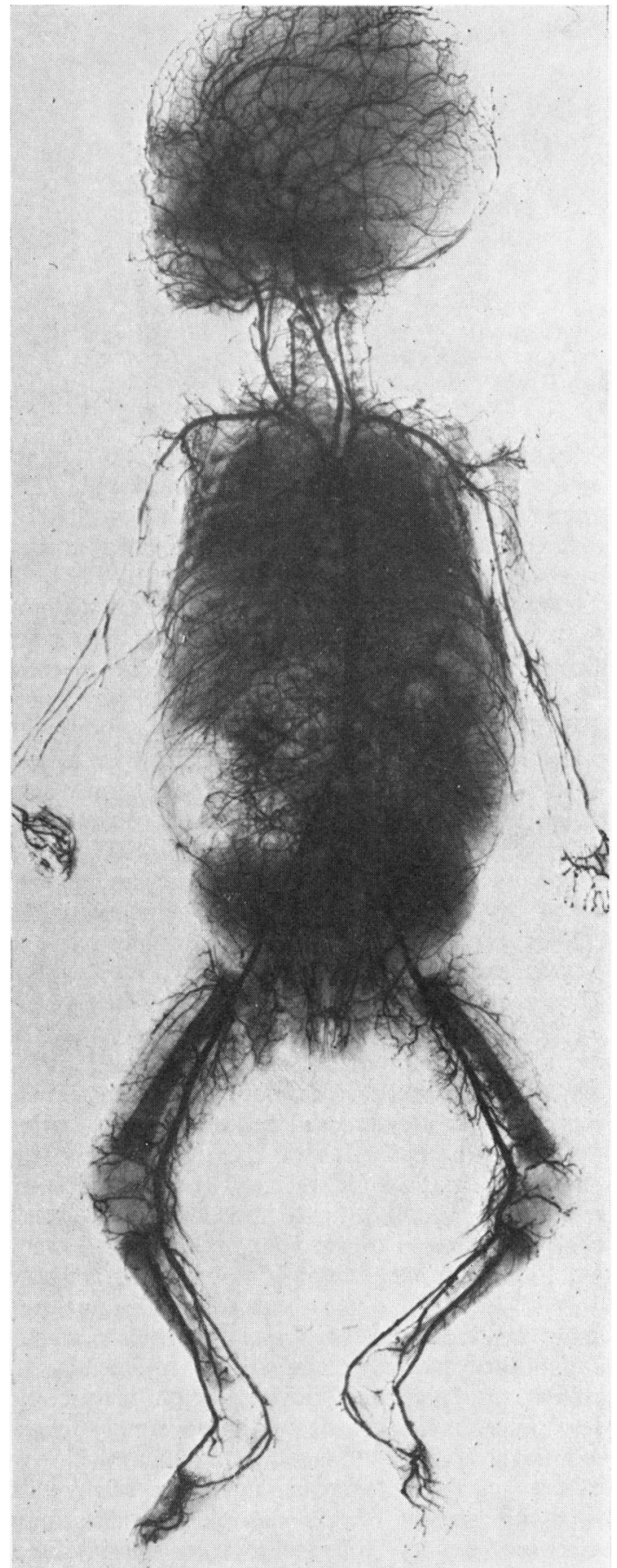

FIG. 1.-Radiograph of whole body showing satisfactory vascular filling.

\section{Method}

A study was made of 15 cadavers, either stillborn or neonatal deaths: the vascular system was perfused and then injected with a solution containing, micropaque, $85 \mathrm{ml}$.; water, $15 \mathrm{ml}$.; gelatin, $2 \cdot 25 \mathrm{~g}$. This solution was found to reach fairly small vessels and on cooling and later fixing stayed within the vessels and allowed dissection. The solution was, of course, radio-opaque and could also be identified visually during dissection.

A mid-line vertical anterior thoracic incision was made and the sternum was divided longitudinally: pericardium was opened and the aorta and pulmonary artery ligated at their origins. Filling of the pulmonary bed could only be avoided by ligating the ductus arteriosus. A catheter was then inserted into the aorta under water and the perfusion commenced after excising the atrial appendages to allow clear vent for the fluid. The body was perfused with $2 \%$ saline to avoid excessive oedema and the total perfusion volume was at least three times the estimated blood volume. The gelatin/barium solution was freely liquid at $47^{\circ} \mathrm{C}$. and the water bath was maintained at least at this temperature. Perfusion was carried out under water to avoid bubbles entering the circulation. After completion of the perfusion a measured quantity of gelatin/barium solution was injected through the aortic catheter, and it was found that one-fifth of the estimated blood volume was a suitable amount for visualization of small vessels.

Radiographs confirmed that the injection was successful (Fig. 1). The body was then refrigerated and after three to four hours a normal autopsy could be carried out. At autopsy the mediastinum was removed and fixed in $10 \%$ formal saline. An anatomical dissection of this part was carried out about a week later, taking further radiographs at various stages of the dissection. Radiographs were made on fine grain (Kodak Crystallex) film so that the film could be used as a negative and enlarged prints made to demonstrate the finest vessels. A plastic tube was inserted to identify the oesophagus in radiographs.

\section{Results}

The blood supply to the oesophagus usually followed the accepted anatomical pattern. There was an adequate supply of vessels arising from branches of the thyro-cervical trunk, deriving from the subclavian arteries; and the lower oesophagus, above the area supplied by the left gastric and left phrenic arteries, received three or four branches from the descending aorta (Figs. 2 and 3). It seemed suggestive that the part of the oesophagus where there was the largest gap between supplying arteries was at the level of the arch of the aorta, which is also the common level of oesophageal atresia.

In one case there was a branch running direct to the oesophagus from the innominate artery (Fig. 4) and in another a branch ran to the oesophagus from a bronchial artery. In another specimen a bronchial 

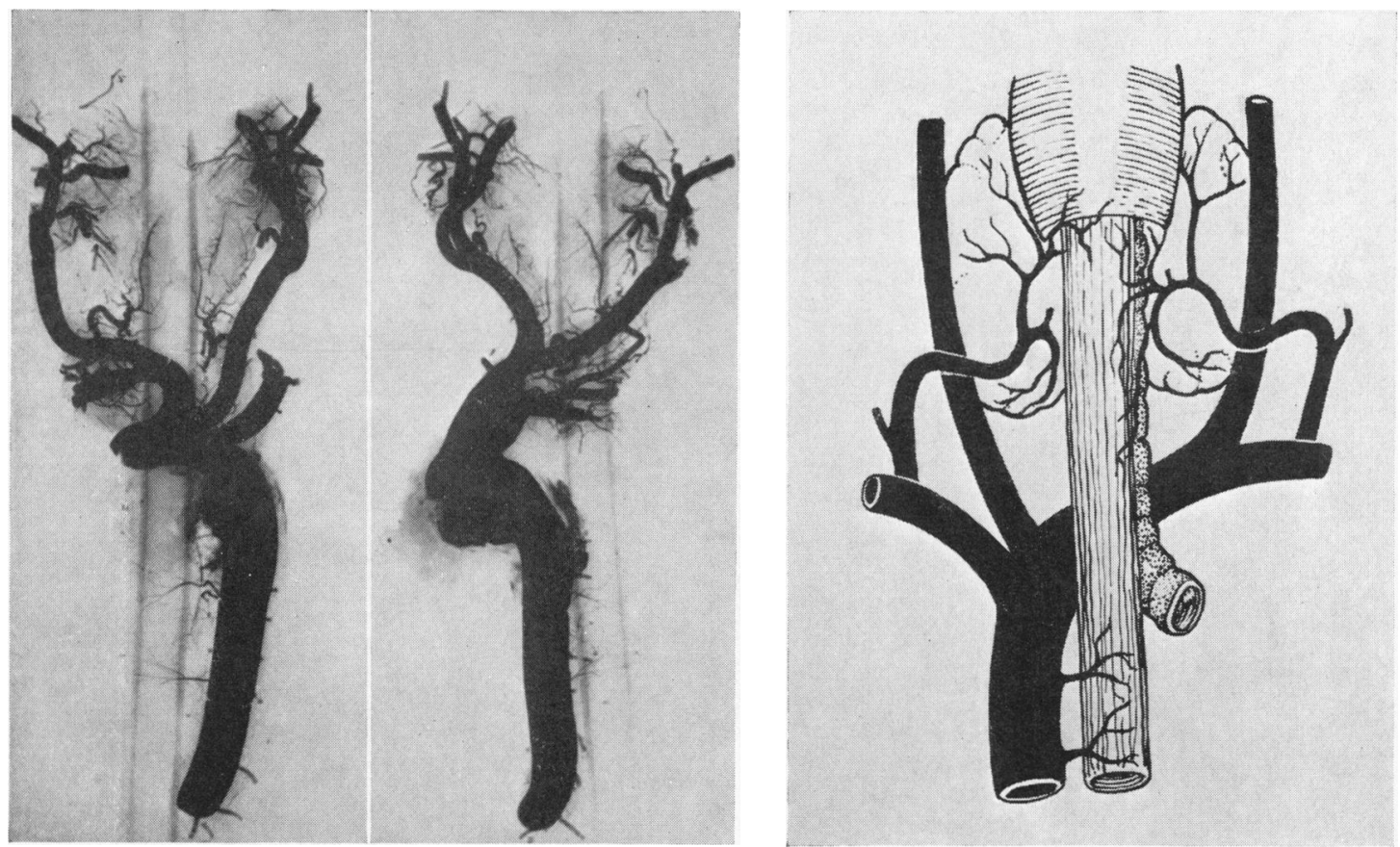

FIG. 2.-Radiograph of injected specimen showing vessels from thyro-cervical trunk and from descending aorta with intervening gap.

FIG. 3.-Diagrammatic representation of blood supply as in Fig. 2 but viewed from behind.

artery was shown crossing behind the oesophagus and dividing into two branches with the bronchi (Figs. 5, 6 and 7): occlusion of this vessel would reduce blood supply to the oesophagus and trachea at the usual level of oesophageal atresia with tracheo-oesophageal fistula.

An opportunity has not yet arisen of injecting a specimen of oesophageal atresia which has not been operated on, but three have been injected who had undergone surgery. The first was an oesophageal atresia of the common type with an associated tracheo-oesophageal fistula. The fistula was divided and an end-to-end anastomosis made at the age of 36 hours, but the child died of pneumonia on the tenth post-operative day; at that stage the child was swallowing, and autopsy showed an intact anastomosis. The radiographs (Figs. 8 and 9) showed remarkably few vessels coming in from the sides of the oesophagus, the anastomosis depending on vessels coming up from the left gastric or down from the inferior thyroid artery. So perhaps this anastomosis, like many, was fortunate to survive.

The second case was a child weighing $2 \mathrm{~kg}$. who already had pneumonia on admission at 24 hours of age. At operation a fairly wide gap was found between upper and lower oesophageal pouches, and there was a fistula between the lower pouch and trachea. There was, however, a right-sided aorta and because the arch of the aorta would have been pulsating over a tense anastomosis it was decided that anastomosis would be unsafe and therefore a gastrostomy and cervical oesophagostomy were made: the child died of pneumonia four days later. Radiographs here showed (Fig. 10) no aortic oesophageal vessels: probably they were divided at operation in mobilizing the oesophagus; but the lower oescophagus still had a good blood supply from the left gastric artery below and a very vulnerable vessel above, which seemed to come down from a bronchial artery.

The third case was a child weighing $1.5 \mathrm{~kg}$. with oesophageal atresia and tracheo-oesophageal fistula, who had the fistula ligated and a gastrostomy and cervical oesophagostomy made. In this case no attempt was made to make an anastomosis and the lower oesophageal segment was not freely mobilized: the radiographs show (Fig. 11) that in these circumstances the oesophageal branches of the descending aorta remain and are entirely adequate for the blood supply of the oesophagus. 


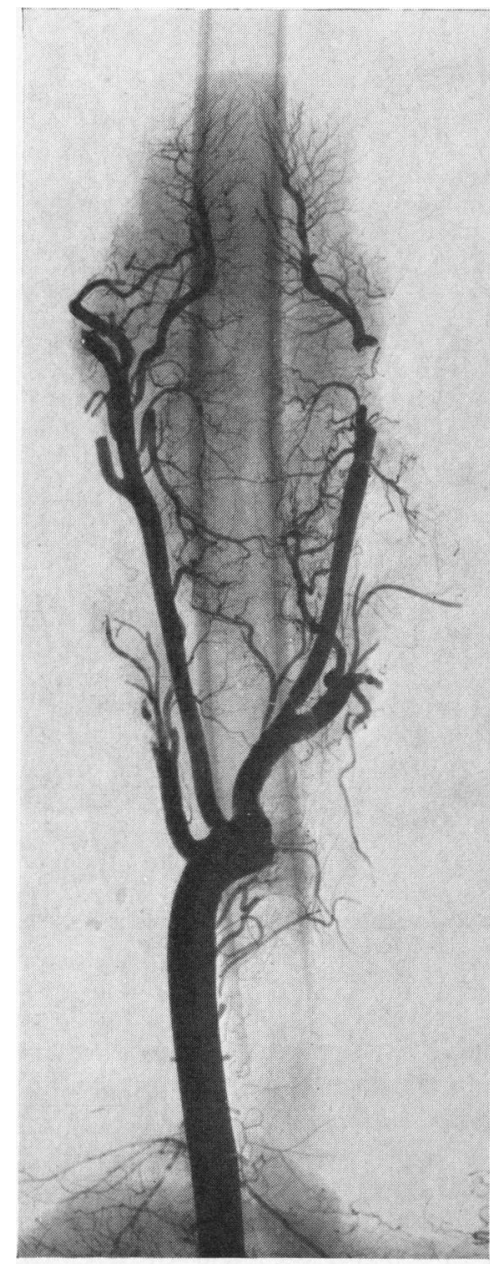

FIG. 4.

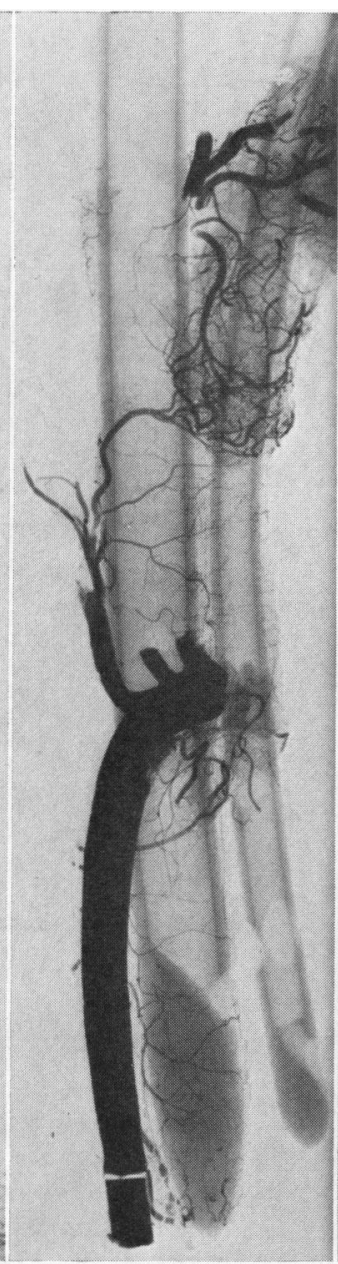

FIG. 5.

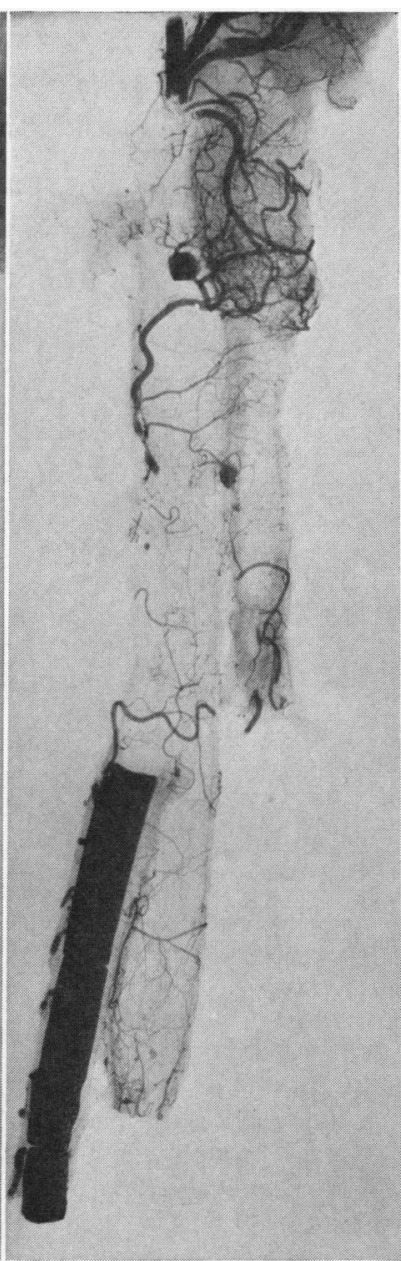

FIG. 6.

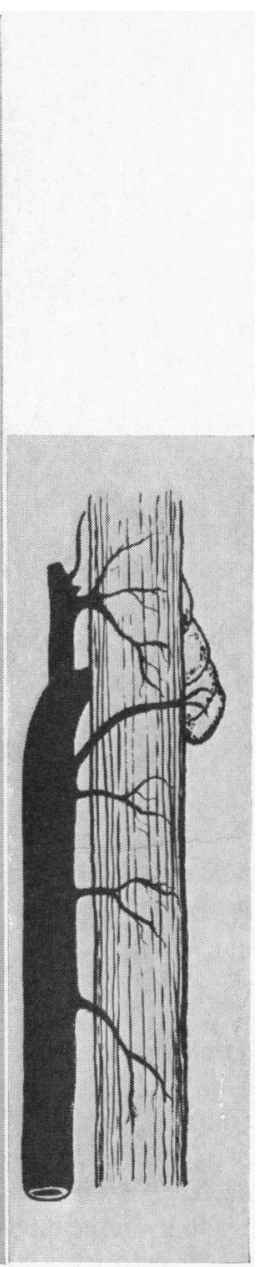

FIG. 7.

FIG. 4.-Specimen showing oesophageal vessel arising direct from innominate artery. Viewed from behind the tube identifies the oesophagus.

Fig. 6.-Further dissection of Fig. 5 with tubes removed showing contiguous blood supply to the oesophagus and bifurcation of trachea.

\section{Conclusions}

At this stage no more has been done than to demonstrate that sometimes the blood supply of the oesophagus is such that a localized vascular catastrophe could produce a lesion such as is found in oesophageal atresia with tracheo-oesophageal fistula. But from the practical point of view the fact is confirmed that in oesophageal atresia, unlike in small bowel atresia, the upper blind loop has a very

FIG. 5.-Radiograph of specimen showing bronchial artery crossing oesophagus to reach carina. Larger tube is in oesophagus showing normal pattern of blood supply. Smaller tube is in trachea and comes out of the left bronchus just below the level of the arch of the aorta.

FIG. 7.-Diagrammatic representation of vessels in Figs. 5 and 6.

adequate blood supply, but the lower segment is not well supplied, and mobilization of the oesophagus may reduce the blood supply to dangerous levels.

It may well be better to have a tense anastomosis with a good blood supply than to have a slack anastomosis with a poor blood supply. Certainly care must be taken to see that the upper end of the lower pouch bleeds after mobilization and, should the blood supply be poor, the oesophagus will have to be trimmed back. 


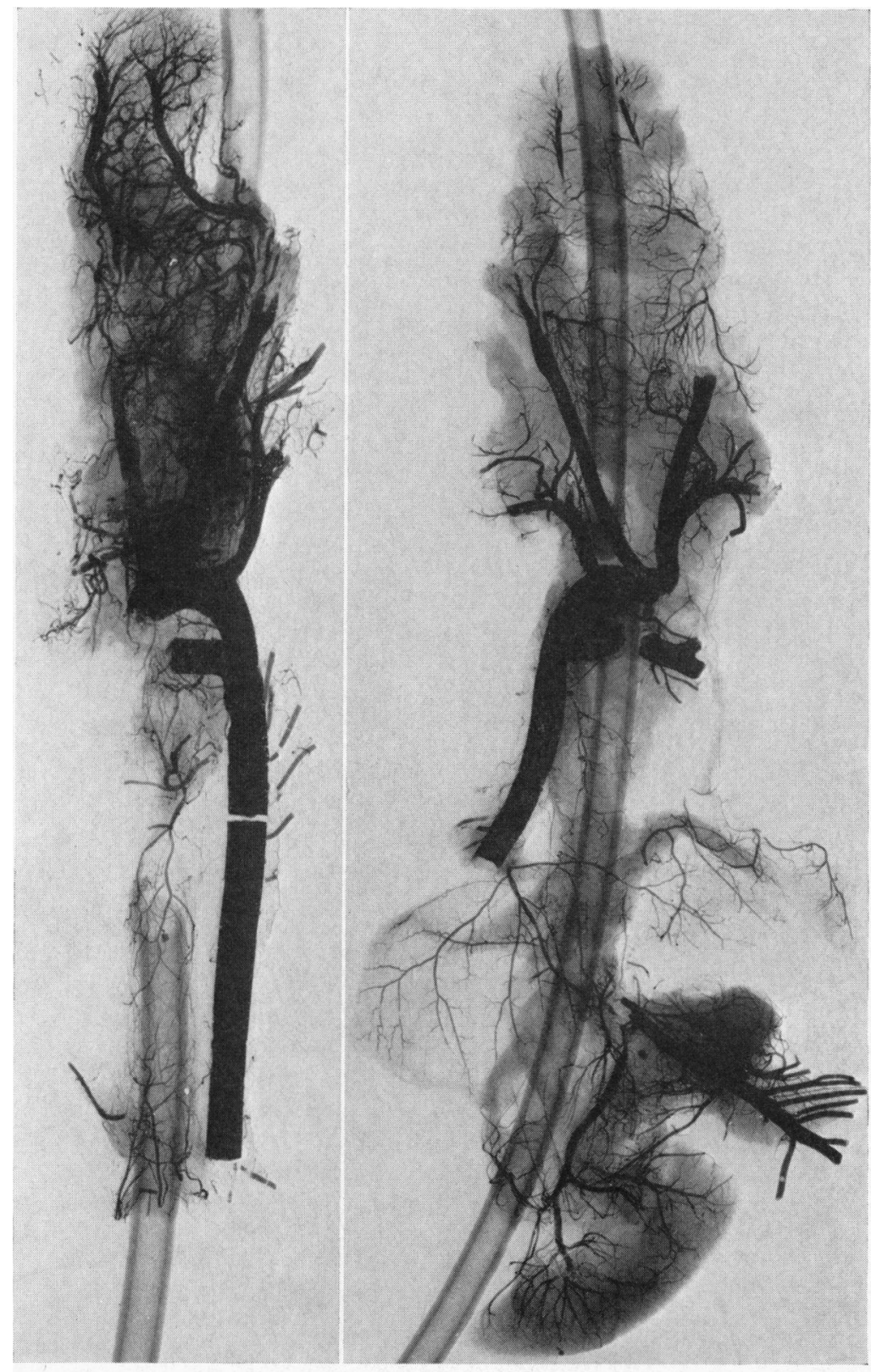

FIG. 8.-Oesophageal atresia and tracheo-oesophageal fistula. Oesophagus anastomosed. Lower segment supplied only by left gastric vessels coming in longitudinally from below.

FIg. 9.-Oesophagus in Fig. 8 laid open demonstrating longitudinal vessels in lower part. 


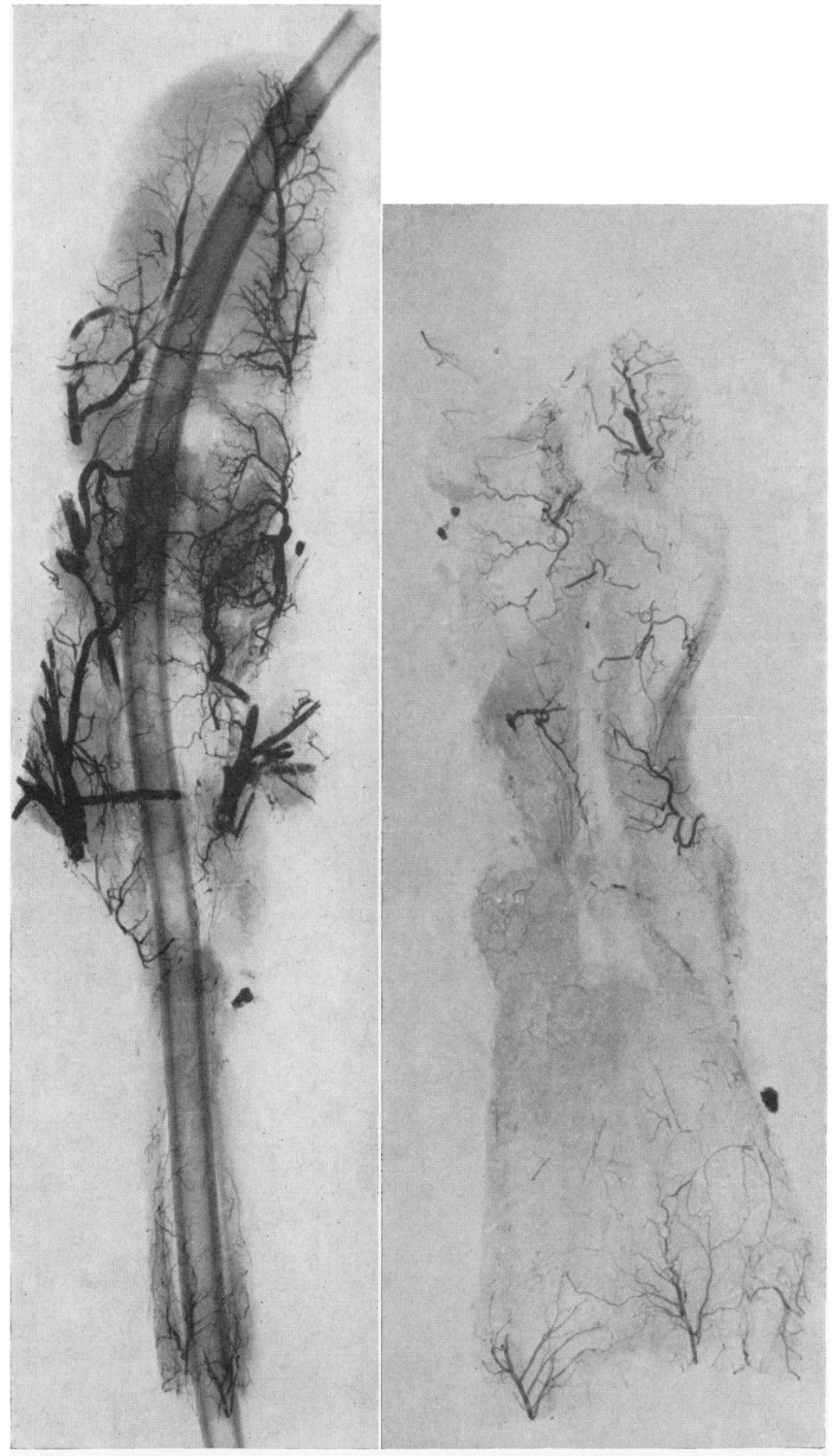

FIG. 10.-Oesophageal atresia and tracheo-oesophageal fistula. Lower oesophagus had been freely mobilized but not anastomosed; it is outlined by tube. Note upper vessel coming down from bronchial artery. Aortic oesophageal vessels missing. Viewed from behindright-sided aorta.

Fig. 11.-Oesophageal atresia and tracheo-oesophageal fistula. Lower oesophagus ligated without mobilization. Usual branches from descending aorta are present. 


\section{Summary}

A technique for the injection of the cadaver to demonstrate blood supply to the oesophagus in the newborn was evolved. The normal blood supply is described with gaps that might have some bearing on the pathogenesis of oesophageal atresia.

The vulnerability of the blood supply to the lower oesophagus is demonstrated, and it is suggested that this blood supply should be preserved, even at the expense of a tense anastomosis, when operating on cases of oesophageal atresia.

This type of work requires the co-operation of the pathologist, which was given in full measure by Dr. N. E. France and Dr. J. L. Emery; it also requires help from the X-ray Department, and I am particularly grateful to Miss D. Wilkinson and to Mrs. E. Abrams, who spent many late hours at the Queen Elizabeth Hospital waiting for dissections and perfecting the radiographic technique.

\section{REFERENCES}

De Garis, C. F., Black, I. H. and Riemenschneider, E. A. (1933) Patterns of the aortic arch in American white and negro stocks, with comparative notes on certain other mammals. J. Anat. (Lond.), 67, 599 .

Fluss, Z. and Poppen, K. J. (1951). Embryogenesis of tracheoesophageal fistula and esophageal atresia. Arch. Path., 52, 168 Johns, B. A. E. (1952). Developmental changes in the oesophagea epithelium in man. J. Anat. (Lond.), 86, 431.

Keith, A. and Spicer, J. E. (1906). Three cases of malformation of the tracheo-oesophageal septum. ibid., 41, 52.

Louw, J. H. (1959). Congenital intestinal atresia and stenosis in the newborn; observations on its pathogenesis and treatment. Ann. roy. Coll. Surg. Engl., 25, No. 4 (November), p. 209.

Tandler, J. (1902). Zur Entwicklungsgeschichte des menschlichen Duodenum in frühen Embryonalstadien. Morph. Jb., 29, 187 
immediately before puberty seems to indicate an increased production of pre-androgens in the adrenal cortex. The total amount of $17-\mathrm{KS}$ and of $17-\mathrm{OH}$ determined simultaneously reaches the values of adults after a gradual increase beginning in infancy.

For their technical assistance we are indebted to Miss Kornélia Ádok and Miss Mária Kazik.

\section{REFERENCES}

Beas, F., Zurbrügg, R. P., Cara, J. and Gardner, L. I. (1962). Urinary $\mathrm{C}_{19}$ steroids in normal children and adults. J. clin. Endocr., 22, 1090.

Bergstrand, C. G., Birke, G., Plantin, L. O. and Zetterström, R. (1954). Adrenogenital syndrome in children: a clinical and steroid metabolic study. Acta endocr. (Kbh.), 15, 210.

Birchall, K., Cathro, D. M., Forsyth, C. C. and Mitchell, F. L. (1961). Separation and estimation of adrenal steroids in the urine of newborn infants. Lancet, 1, 26.

de Courcy, C. (1954). Studies on the fractionation of urinary 17-ketosteroids in children. $J$. Endocr., 11, iii.

Devis, R. (1951). Méthodes chimiques et applications cliniques du fractionnement chromatographique des stéroides urinaires. Ann. Endocr. (Paris), 12, 451.

Dorfman, R. I. (1954). Neutral steroid hormone metabolites. Recent Progr. Hormone Res., 9, 5.

- (1959). Metabolism of androgens. In Proc. Fourth Int. Congr. Biochem., Vienna, 1958. Vol. 4. Symposium IV: Biochemistry of Steroids, p. 175.

Eagle, J. F. (1952). Dehydroepiandrosterone and similar substances in urine of premature infants. Proc. Soc. exp. Biol. (N.Y.), 81,571 .

Faredin, I. and Blahó, G. (1958). Untersuchungen der neutralen 17-Ketosteroids. Z. ges. inn. Med, 13, 339.
Fehér, T., Koref, O. and Holló, I. (1962). Paper chromatography of the neutral 17-ketosteroids in normal human urine. Acta med. Acad. Sci. hung., 18, 235.

Gallagher, T. F. (1957). On alterations in adrenal function, especially with adrenocortical carcinoma. Cancer Res, 17, 520.

Huis in't Veld, L. G. (1957). La Fonction Endocrine du Testiculaire, p. 41. Masson, Paris.

International Union of Pure and Applied Chemistry (1958). Nomenclature of Organic Chemistry, 1957, pp. 73-82. Butterworth, London.

James, V. H. T. (1961). The excretion of individual 17-ketosteroids by normal females. J. Endocr., 22, 195.

Johnsen, S. G. (1956). Fractionation of urinary 17-ketosteroids. Acta endocr. $(K b h), 21,127,146,157$.

Koref, O., Fehér, T., Juvancz, J., Foldes, F. and Fischer, J. (1964) Determination of urinary 17-OH-corticoids using the modified Reddy-method. In the press.

Masuda, M. and Holmes, T. H. (1957). Studies on ketosteroids in urine of normal children using alumina chromatographic fractionation. Pediatrics, 19, 424.

Paulsen, E. P. and Sobel, E. H. (1960). In Advance Abstracts of Short Communications, First International Congress of Endocrinology, Copenhagen, 1960. Periodica, Copenhagen. [Acto endocr. (Kbh.), 35, Suppl. 51, p. 337.]

Prout, M. and Snaith, A. H. (1958). Urinary excretion of 17-ketosteroids in children. Arch. Dis. Childh., 33, 301.

Reddy, W. I. (1954). Modification of the Reddy-Jenkins-Thorn method for the estimation of 17-hydroxycorticoids in urine. Metabolism, 3, 489.

Ulstrom, R. A. and Doeden, D. (1956). Chromatographic studies of urinary steroids in term and premature infants. In Adrenal Function in Infants and Children, ed. L. I. Gardner, p. 31. Grune and Stratton, New York.

Wilkins, L. (1962). Adrenal disorders. I: Cushing's syndrome and its puzzles. II: Congenital virilizing adrenal hyperplasia. Arch. Dis. Childh., 37, 231.

Zimmermann, W. (1955). Chemische Bestimmungsmethoden von Steroidhormonen in Körperflüssigkeiten, p. 63. Springer Berlin, Göttingen, Heidelberg.

\section{Erratum}

It is regretted that in the paper by $\mathbf{J}$. Lister on 'Blood Supply and Oesophageal Atresia', which appeared in the previous issue (Arch. Dis. Childh. (1964), 39, 131), Figs. 8 and 9 on page 135 should have been labelled Figs. 10 and 11 , and Figs. 10 and 11 on page 136 should have been labelled Figs. 8 and 9. 